\title{
Critical Review of Literature on Cultural Diversity in the Work Place and Organizational Performance: A Research Agenda
}

\author{
Emily Nyanchama Ayega, Stephen Muathe \\ School of Business, Kenyatta University, Nairobi, Kenya \\ Email address: \\ emilyayega10@gmail.com (E. N. Ayega), muathesm@yahoo.com (S. Muathe)
}

\section{To cite this article:}

Emily Nyanchama Ayega, Stephen Muathe. Critical Review of Literature on Cultural Diversity in the Work Place and Organizational Performance: A Research Agenda. Journal of Human Resource Management. Vol. 6, No. 1, 2018, pp. 9-17.

doi: $10.11648 /$ j.jhrm.20180601.12

Received: January 8, 2018; Accepted: January 20, 2018; Published: February 15, 2018

\begin{abstract}
Cultural diversity is what binds all groups of employees at all levels in a company. Cultural diversity calls for a type of organizational culture where all members can pursue their aspirations without being inhibited by gender, race, nationality or other qualities that are irrelevant to performance. The importance of the need to have the concept of managing diversity embraced by top managers has also been emphasized. A statement concerning diversity should always refer to certain facets such as age, gender, culture and disability. Scholars have not concentrated more on cultural diversity in the workplace and how it affects organizational performance, hence creating a gap. This study provides background knowledge on cultural diversity among employees at the workplace and provides measures of organizational performance. The study further brings out the study theories under theoretical review, which comprises the resource-based theory, behavioural theories and competency theory. This study reviewed various literatures on cultural diversity in the workplace and organizational performance and found that cultural diversity in the workplace is a formidable competitive weapon in an organization. The study recommends that organizations should have proper cultural diversity management since it enables an organization to achieve a competitive advantage, which in turn influences organizational performance. In addition, the paper recommends that organizations should effectively manage their cultural diversity. This is because it has been established that cultural diversity influences organizational performance.
\end{abstract}

Keywords: Cultural Diversity, Workplace, Organizational Performance, Resource-Based Theory

\section{Background}

In today's world, globalization has almost removed national boundaries, making labour movement easy and further forced organizations to deal with people of diverse cultural backgrounds. A multicultural workplace has made Human Resource Managers deal with a set of new challenges as a result of much-needed changes in management practices. The aspect of increasing diversity and heterogeneity is beneficial if it is effectively managed. Diversity is quite an emergent field of research which began in the 1960s during the anti-discrimination movements in the United States of America (USA). Diversity began receiving attention in scientific literature in the 1990s [15].

However, constructs need to be defined conceptually or constitutively since they are ideas that help to organize a domain of study, else it will be impossible in generation of knowledge in the domain under study. In today's corporate world, customers are putting consideration on the speed of delivery of solution as one of the key components in determining a solution provider. Therefore, industries, regardless of their field, start to search for new methods of boosting the performance of the organization and for developing solutions to the challenges faced by their businesses. For this reason, organizations are thinking around the inclusion of workforce diversity against the monolithic structures that have traditionally been in place. In many states, staffs comprise people of different nationalities, cultures, generations and genders. Countries like Singapore have been positioned as being attractive foreign investment 
destinations because of their mature and experienced workforce as a result of multiculturalism. There is a range of opportunities created by the mix of competencies resulting from a broad diversity. Therefore, this workforce diversity is considered as a valuable component for building contact with businesses from all corners of the world and for making it possible for foreign groups to engage their business within their locations.

In a similar way that the performance of an organization is massively influenced by the performance of one employee, the positive outputs of a diverse workplace force at the staff level would also be intrinsic as well as an extrinsic motivational factor for the staff. This would hence boost staff participation. It is on the basis of this that organizations pay close attention to the staff's attitude acquired through individual experience while interacting with workforce diversity at the workplace, with reference to age, gender and ethnicity in their organizational setting. Research done by past scholars portrays diversity as beneficial to performance under facilitating context; on the other hand it is detrimental under obstructing context. On this basis, numerous studies give the status of diversity in the workplace environment. An attempt is also being carried out to point out potential solutions that staff consider would boost the benefit of workplace force diversity to the next level [28].

When organizations comprehend the advantages of diversity, work put constrainturns into a vital resource and when overseen well, could likewise encourage the organization's prosperity. A few organizations measure performance by evaluating the stewardship of the best administration or how effective the organization uses its assets to create a benefit. Since the period considered is typically short, these measures can be translated as markers of how all-round fitted the organization is to current conditions. Others measure performance in view of the overarching cost of an organization's stock. The productive markets speculation expresses that the stock cost increased by the quantity of offers is the best accessible gauge of the genuine estimation of an organization [18]. A few examinations have demonstrated that group heterogeneity affected performance relying upon the measure of heterogeneity chosen [2].

\section{Theoretical Review}

\subsection{Theoretical Literature}

There are several theories that explain how cultural diversity in the workplace would ensure organizational performance. This paper is based on the following three theories that underpin the study: resource-based view, behavioural theories and competency theory.

\subsubsection{Resource-Based Theory}

The theory was advanced by Penrose, who viewed a firm as a bundle of resources and argued that it is the heterogeneity of resources that give each firm its unique character [29]. The focus therefore is on the assets of the firm and specifically people, since they have been viewed as being vital in the attainment of sustainable competitive advantage. Asset-Based View (ABV) of the firm, is therefore established on the conviction that organizations inside an industry direct heterogeneous considered assets. Assets are for the most part resources, capacities, organizational procedures, firm properties, data, information, and so forth controlled by a firm that empower the firm to catch and actualize systems that propel its productivity and adequacy [1]. Expressed in an unexpected way, assets are the qualities that enable firms to actualize their procedures. As indicated by the ResourceBased View (RBV), certain benefits with specific highlights will prompt legitimate preferred standpoints.

In any case, an asset-based view procedure can't convey upper hand without being operationalized. Operationalization implies a formalization of the hypothesis' thoughts and ideas into pertinent models, which empower all phases of technique detailing and basic leadership [1]. The operationalization of RBV hypothesis is key since it directs managers in their asset-based procedure execution. In Penrose's view, the administration's part is two-fold: the organization of assets, and administration as an asset parse, taking the supposition that managers convey and procure administrative assets and capacities. Both are firmly related on the grounds that administrators as assets render administrations for the administration of different assets. Likewise, the critical part of managers is instructed by the view that with respect to every different sort of beneficial administrations, administrative administrations are the main sort which each firm, on account of its exceptional nature as an authoritative association, must make use of [11].

A firm has an unobtrusive favourable position or competitive advantage over another firm when this preferred standpoint isn't being acknowledged by any contender [1]. In analysing sources of competitive advantage, the Asset-Based View has two assumptions [1]. Firstly, a firm within an industry may be heterogeneous with respect to the strategic resources it controls. Secondly, the model assumes that these resources may not be perfectly mobile across firms, and thus heterogeneity can be long lasting. The asset-based model of the firm examines the repercussions of these two suppositions for the analysis of sources of sustained competitive advantage.

Operative resource-based models should provide guidelines for resource identification and selection and address the dynamic aspect of bundling resources [7]. Hence, they have to face biases and errors arising from uncertainty, complexity, and organizational conflicts. Resource-based models support strategy design by providing operative tools that make it possible to trace consequences of different strategies. Therefore, operational resource-based models should "reveal flaws and inconsistencies in proposals that might not otherwise come to light until the proposals are implemented and under way" [7]. To do this, operative resource-based models must embody four characteristics: provide guidelines to identify and select valuable resources, portray the resources' intrinsic endowment dynamics, depict 
how managerial policies affect resource management and have the ability to trace consequences of potential strategies over time.

The resource-based view distinguishes two variables that determine whether a resource is strategic or not: the imitability of a resource and imperfect mobility, contribute to the uniqueness of a resource and with this uniqueness to a potential sustained competitive advantage [1]. When a resource can be imitated by a current or potential competitor, the firm loses the opportunity to gain a sustained competitive advantage. In other words, the company loses uniqueness [13]. Imitability can be impeded by the following three factors: unique historical conditions. A leading company in technology development may be too large to be overtaken by potential and current competitors.

This is because the leading company is more knowledgeable and developed and therefore, these potential and current competitors are probably not able to overtake the company. Causal ambiguity occurs when imitators do not know what to imitate, because they cannot draw a causal relation between the success of the "successful" firm and the actions of that firm. Social complexity arises when resources can be socially complex in a way that other firms are not able to manage and influence these resources themselves. Examples of social complexity include a firm's organization culture and social networks [13].

Imperfect mobility occurs when a resource that can be bought by another firm on a market cannot result in a competitive advantage. For example, a machine that can be bought on a market by firms cannot be unique for one of the buyers of that machine. Examples of resources that can be unique are property rights and reputation; other firms on a market cannot buy these unique resources. An abstract form of immobility is imperfect mobility [1]. Imperfect mobility makes certain resources more valuable to one firm compared to another firm. An example could be a product developer in a product-developing team. The value of the product developer separate from the product developing team is lower than the value within his team. So, when a competitor is interested to "buy" the product developer, he or she will be of less worth to the competitive firm since he or she performs best in the product-developing team of the current firm.

\subsubsection{Behavioural Theories}

Valence alludes of the discerned quality that an individual spots around required remunerates. Instrumentation may be that association in the middle of unique execution and the normal remunerates. Anticipation intimates the individual's conviction that an undertaking will make performed during a particular level from claiming achievement. Anticipation principle contends that representative recompense may be proportional to their level from claiming performance, and subsequently is a sourball of work fulfilment. An error will prompt disappointment. A representative a firm might choose will finish an assignment dependent upon those discerned equitability of the compensation, if such recompense may be fiscal or non-monetary.
Goal theory explains job satisfaction by the awareness of employees that the task being completed will help achieve a goal [30]. The assumptions of the goal theory are that specific goals are superior to general goals, and difficult goals lead to greater performance. Goal setting leads to job satisfaction through a series of processes that involve existents (incentives, objects, actions, outcomes); evaluation (cognition, values), emotions and desires; anticipated existents (incentives, objects, actions, outcomes); judged instrumentality of anticipated action and anticipated effect such as goal setting and action [20].

Situational theories argue that there are situational factors that influence job satisfaction, and such factors result from the job's characteristics. The assumption is that people have similar needs, and therefore can be satisfied by the same job characteristics. Some of the situational theories follow the job characteristics model and the operant approach [8]. The situational occurrences theory argues that an individual's job satisfaction depends on a combination of situational characteristics and situational occurrences [31]. Situational characteristics are characteristics that an individual considers before accepting a job offer (wages, working conditions, supervision, promotion and organizational policies). Other situations that an individual considers while in the job are called situational occurrences. The situational occurrences can be positive (for example, giving an employee an unexpected pay increase for completing a task outstandingly) or negative (co-workers are constructing roadblocks that prevent an employee from efficiently completing his or her assignment [20].

The job characteristics model explains that there are five core job characteristics (skill variety, task identity, task significance, autonomy, and feedback from job) that influence the outcomes of job satisfaction (high internal work place motivation, high growth satisfaction, high general satisfaction, and high work place effectiveness). Job satisfaction outcomes are moderated through critical psychological states (experienced meaningfulness, experienced responsibility for outcomes, and cultural diversity of actual results) like other moderators, such as knowledge, skill, growth, and need strength [8].

\subsubsection{Competency Theory}

The theory of competency builds on the indispensability of management in its view of firms as open systems that are guided by a strategic logic derived from managerial cognitions and governed by management processes that coordinate asset stocks and flows. The competency perspective has emphasized the importance of organizational resources and capabilities, particularly organizational knowledge. The resource-based approach to firm strategy portrays a firm as a collection of tangible and intangible assets, resources or competencies which are tied to the firm and are difficult for others to imitate. A firm's competencies is a set of differentiated technological skills or complementary assets and organizational routines that provide the basis for a firm's competitive capacities in one or 
more business area [23]. Externally, these competencies may be perceived as skills in a particular product area.

However, a competency is the ability of a firm to solve organizational and technical problems, and thus is not limited to a specific set of products. Indeed, firms frequently possess competencies that extend into multi-product space. Examples of time-specific competencies include employment of skilled personnel and in-house knowledge of cultural diversity of technology, operating routines and trade contacts. These resources arise primarily through organizational learning. As a result, they are closely tied to the products and markets in which the firm has historically been active. These resources enable firms to have markedly lower costs or to offer higher quality products and performance than competitors. To the extent that resource endowments are sticky, firms with superior competencies will tend to be more profitable than competitors [23].

To be acknowledged a source of competitive advantage, an organizational competency must meet three conditions: it must be heterogeneously conveyed inside an industry. A firm's organizational competency can be divided into three components: allocated competencies - the decisions involving what to produce and how to price it, transactional competency- decisions on whether to make or to buy and whether to do so alone or in a partnership, and administrative competency - how to design organizational structure and policies to enable efficient performance [8]. Additionally, the authors define technical competency as the ability to design and develop products and processes. It is also the ability to operate facilities effectively [20].

In the search to explain the competitive successes of firms, management scholars have paid attention to knowledge resources and knowledge-creation processes as primary sources of competitive advantage. Because knowledge serves as the base upon which capability is formed, knowledge may create barriers to imitation by rivals. Knowledge may therefore account for the larger part of a firm's added value as knowledge has been characterized as the most strategically significant resource of the firm [32]. In dynamic environments, knowledge creation processes are especially crucial, because new knowledge resources enable a firm to respond to the changing demands imposed by the environment over time.

Besides absorbing new external knowledge [6], two additional ways of creating knowledge at the organizational level are the replication of knowledge among organizational members without alteration of its content [12] and the integration of different kinds of knowledge into a new body of knowledge [32]. In knowledge integration processes, individuals' specialized knowledge serves as the basis of their ability to perform individual tasks. These specialized capabilities of individuals must be integrated to create organizational capabilities [32]. In this process tacit knowledge is the necessary component of all knowledge and to split up tacit and explicit knowledge is to miss the point; the two are inseparably related [24]. Tacit knowledge often takes the form of rules and routines, and much explicit knowledge is built on a foundation of tacitly shared knowledge.

Knowledge and knowledge creation focuses on organizational processes. In so doing, discussions of knowledge and knowledge creation are often focused on the way in which knowledge makes it possible to earn profits and rents through its deployment and application to products and services. Grant illustrates the need for knowledge to be integrated to form an organizational capability by analysing processes of knowledge integration in a manufacturer of private-branch telephone exchanges [32]. To manage knowledge and knowledge creation effectively within an organization, "managers need to understand not just the stocks of knowledge within the firm... but also how to manage the actual and potential transfers and diffusions (flows) of knowledge within and across the boundaries of the organization".

Accomplishing this requires recognizing the basic differences in the contents of various kinds of knowledge. Know-how, know-why, and know-what forms of knowledge that corresponds to state, process and purpose forms of knowledge about a system, respectively can be distinguished. The concept of a product as a system can be developed, but of course, the concept of a system can also include any technical method or function, the firm itself, and its environment. Know-how is practical knowledge about "how elements of a system are interrelated in the current state of the system." Know-why is knowledge about why the parts of a system work together; this is the theoretical knowledge needed to understand how component parts can be configured in a system design to produce some overall function. Know-what is characterized as strategic knowledge about "what courses of action are available to a firm" for using its know-how and know-why forms of knowledge [25].

In an organizational context, know-how is knowledge about how the elements of an existing system are related to each other, and therefore resembles a practical or procedural form of architectural knowledge about an organization. Know-why, then, is knowledge about why the elements of an organization function together and enable the organization to work in the way it does. Analogously, know-what is managerial knowledge of the strategic purposes which could be accomplished by applying know-how and know-why knowledge about an organization [33].

\subsection{Empirical Literature}

Various studies have been reviewed such as that of Dike [5], which established how workplace diversity affects organizations. Workplace diversity is the topic of this study. This study looks at the effects of workforce diversity and how it affects the presence of organizations and how its arrangement and challenges from different social foundations experienced by employees affect organizational performance. Therefore, the main purpose of the study was to find out how workplace diversity adds to the success of the organization. Five organizations in Finland and Ghana have been contemplated so as to gain answers to the inquiry which this 
study is centred around.

To collect the required information for this theory, the researcher has for the most part utilized the present material that contains Human Resource Management research gaps. Subjective research technique has been utilized to accumulate and investigate the information on the organizations. To answer the examination question and additionally acquire viable and significant data on each organization, the creator directed a meeting in three of the organizations, and assembled data on the web on two of the organizations. The outcome demonstrates that workplace diversity assumes a compelling part in a few organizations. However, lack of coaching and direction could cause low profitability in an organization. Thus, there must be customary change in approaches to viably deal with a diverse workforce as the world continues progressing.

Wambari determined workplace diversity administration impacts on execution of human asset administration in the Ministry of Health, Kenya [26]. The examination assessed literature from hypothetical and empirical reviews that considers last traces of the calculated structure of model. The ministry headquarters are situated in Afya House, Nairobi and the investigation focused on a population of 168 employees from different divisions in the ministry with an examination test size of 34 respondents from all units of business. The scientist utilized stratified arbitrary testing to think of the examination test of $20 \%$. The researcher employed descriptive research design and a self-administered questionnaire using drop and pick later method of distribution. Content validity was used to measure validity of the research instrument that facilitated the researcher to seek assistance from an expert or professional opinion and input from the supervisor. Generally, Likert scale, and open and closed ended questions were used in the study questionnaire. The collected data was analysed, coded, processed through SPSS software and reliability test measured by Cronbach's Coefficient Alpha Model.

Presentation was done by the use of mean, median and standard deviation, which are descriptive measures. Later, cumulative and frequency distribution tables, bar graphs, pie charts and line graphs were used to present the data obtained. Multiple regression, which is an inferential statistic, was used. Gen X (34-48 years) represented the majority, which is the workforce, and a mean of 42 years was used to represent the young generation between 22-37 years. Adherence of policies in recruitment, equitable and fair implementation of other Human Resource Management (HRM) practices and provision of conducive and enabling environment for employees are the positive factors that reflect diversity in management. The mentor-building of the minority young generation needs thorough and effective mentor-building and effective succession plans. A close relation was identified by the results of P-value (0.03) which showed that a close relationship exists between the variable and implementation of (HRM) practices, which was also clearly indicated by the independent $t$-test showing significant levels and which was also further clearly indicated by the independent t-test showing significant levels. The study projects a growing number of Generation $\mathrm{X}$ and upcoming Generation $\mathrm{Y}$ in the workforce who are facing out the experienced and skilled baby boomers.

The upcoming future generation may likewise incorporate gifted and socially unsatisfactory workforce of gays and lesbians, therefore raising worries of how to execute adaptable work approaches and work practices to oblige the changing workforce needs. This would also be necessary in order to suit female employees who have substantial local duties of raising and looking after children and comprise the biggest number of talented working mothers in the workforce. It is normal that such employees would help beat ability and befuddle of occupations in the global market as effects of work turnover and aptitudes and gifts that are out of date. The author at last prescribes associations to prepare and coach their up and coming ages to conquer such difficulties for future best officials and keep up fruitful organizations in the period of globalization and testing developing innovation and culture.

Astrid, Daniela, Marina, Cornelia and Karen did a study on dealing with a socially diverse workforce: Diversity viewpoints in associations [10]. The creators directed two investigations to examine why and how organizations approach and oversee social diversity in the Austrian workplace and to recognize organizations' points of view on diversity. In Study 1, 29 interviews uncovered experiences into organizational ways of dealing with diversity and how these points of view are connected to utilizing and dealing with a socially diverse workforce. In Study 2, the creators created and tried the Diversity Perspective Questionnaire (DPQ). The DPQ comprises vignettes and things to quantify an organization's way of dealing with diversity. Results uncover that five diversity viewpoints - reinforcing homogeneity, colour-blind, fairness, access, and integration and learning - pick up a more profound comprehension of diversity administration in organizations. The DPQ appeared to be a dependable estimation instrument for advance examinations of organizations' points of view on diversity.

The benefits and challenges of workplace diversity management were assessed through a case study of Consultative Group on International Agricultural Research (CGIAR) centres in Kenya [10]. This study sought to assess the benefits and challenges associated with the workplace diversity management at CGIAR centres in Kenya. The objectives of this study were to establish the benefits of workplace diversity management and to determine challenges of diversity management at the Consultative Group on International Agricultural Research centres in Kenya. To achieve these objectives, the study used a questionnaire and an interview guide to collect primary data from 12 respondents at CGIAR centres in Kenya. Data collected was analysed using descriptive statistics and results presented in tables and figures.

The study found that high performance is exhibited where teams have diversity in terms of age, ethnicity, nationality, gender and other differences. Employee diversity was also 
found to enrich knowledge and skills of the organization as well as improve organizational creativity. It was revealed that workplace diversity is not fully entrenched in CGIAR Kenya centres. On the benefits of workplace diversity, it was found that women empowerment has seen more women managers being included at management level. The trainings offered have empowered employees by providing them with knowledge on how to live in multicultural environments. Workplace diversity management was also found to have impacted positively on the employees' career growth and improved on their interpersonal skills in a working environment.

Dhakshayene and Anneli established social diversity in organizations [4]. So as to pick up experiences into this inquiry, past research has been explored and some fundamental speculations have been chosen. Through this, it has been discovered that social diversity is a perplexing subject that can cause both positive and negative impacts in an organization. These thus influence how social diversity is seen by that organization. Besides, this view influences how social diversity is overseen, and the administration thus influences the outcome this idea conveys to the organization. This has thus been spoken to in a hypothetical model speaking to the connection between these ideas. The primary hypothesis that is utilized all through the examination and in investigating the observational information is Adler's ways to deal with answers to the exploration question.

This study takes perspective of interpretive and constructionist as its philosophical position. This has prompted the decision of leading a subjective research approach with blended technique that is a mix of both the deductive and inductive methods of gathering information. The exploration is directed through various contextual investigation outlines with semi-organized meetings as the method for increasing observed information. These meetings have been directed on seven organizations inside Västerbotten that speaks to various sorts of businesses inside this area. As it appears in this investigation, social diversity is seen emphatically and figured out on how to accomplish cooperative energy inside the organizations in Västerbotten. The organizations trust that while keeping in mind the end goal is to create and increase upper hand, they have to suit to social diversity and make a climate that is open and adaptable. Still, the greater part of the organizations do not have the all-encompassing perspective as they neglect to express diversity at the vital level and thus in all measurements of the organization.

Similarly, the investigation has distinguished distinctive compelling variables of social diversity, for example, the topographical area, organizational culture, clients' diversity and supervisors' viewpoints influence the presence of social diversity inside an organization. These discoveries have been displayed in the created expository model in the conclusion.

Pieters established the powerful administration of a socially diverse workforce in five-star multinational hotels: a contextual investigation, the Westin Dublin [34]. Globalization has quickly expanded the level of social diversity found in organizations. Particularly in five-star multinational hotels where geocentric enrolment is normal, social diversity assumes an imperative part. This is on the grounds that (1) the workforce is diverse, (2) visitors are diverse and (3) supervisors are relied upon to have the capacity to move and surpass in various properties. In this thesis, the peruser will discover an inside and out writing survey and essential information through meetings led for the situation organization hotel. The essential and auxiliary information is utilized to give present and future managers with understanding and proposals in the matter of what the basic variables are in effectively dealing with a socially diverse workforce in five-star multinational hotels.

This examination has taken a subjective, inductive, interpretivist, exploratory, cross-sectional outline as a contextual investigation, which was the most suitable approach for this sort of research in light of the fact that the utilization of proficient administration of social diversity is a social marvel, which has turned out to be progressively powerful, as the world has kept on globalizing. Holes and inconsistencies and in addition similitudes were found between the writing audit and the essential information, which is taken a gander at long in the discourse and conclusion sections. In light of the discoveries in this thesis, the scientist has formulated a model that structures the most vital components in successfully dealing with a socially diverse workforce. It is known as the 3 As of successfully dealing with a socially diverse workforce - to Act, Acknowledge and Accredit. A standout amongst the hugest discoveries was that while culture matters, it appears it is most critical to become more acquainted with and comprehend the person to adequately lead them towards accomplishing the group objectives.

\section{Findings and Discussions}

This paper has reviewed literature on the concepts and found that cultural diversity in the work- place is a formidable competitive weapon in the organization. In addition, cultural diversity affects all other organizational functions and hence has become a subject of interest to all levels of management in an organization. Further, the paper has established that cultural diversity is an intangible and difficult to imitate asset of an organization comprised of useful information that other people have no access to and are incapable of using. Creating diversity management involves making decisions and coordinating activities facilitating the actual processes of creating core benefit for the organizational performance. Value creating processes take place both inside an organization and in its external environment in collaboration with business partners and suppliers.

From the review of the paper, the literature suggests that there is a positive relationship between cultural diversity in the workplace and organizational performance. However, there are several unexplored questions to be answered. It would be useful to research the relationship between managers' view on cultural diversity and its influence on 
management of cultural diversity. The reason and the causes of no representation or poor representation in terms of equality instead need to be further studied. Finally, the relationship between positive and negative effects of cultural diversity needs to be studied in relation to the different cultures represented in an organization.

\section{Proposed Conceptual Framework}

This paper proposes a conceptual framework below that demonstrates the linkage between cultural diversity in the workplace and organizational performance. The proposed conceptual model shows a direct causal relationship between cultural diversity in the workplace and organizational performance. Environmental circumstances such as technological factors, dynamism and regulation mediate the relationship between cultural diversity and organizational performance; furthermore the moderating variable shows the effect of organizational factors on cultural diversity and organizational performance. The linkage between the variables is explained in the diagram below.

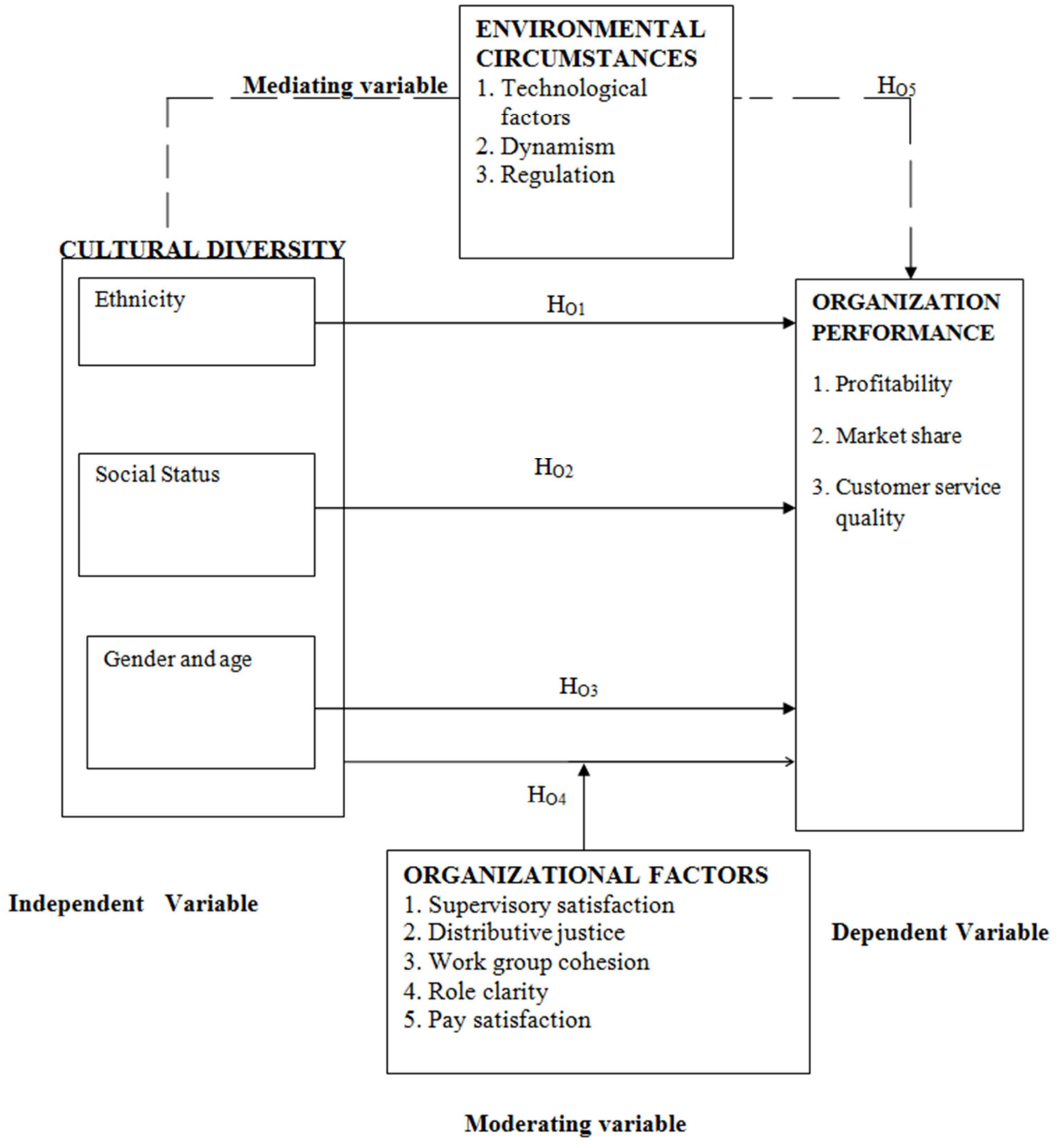

Figure 1. Proposed Conceptual Framework.

The paper provides the following hypotheses as a description of the conceptual framework:

i. There is no significant relationship between ethnicity and organizational performance.

ii. There is no significant relationship between social status and organizational performance.

iii. There is no significant relationship between gender and age, and organizational performance.

iv. There is no significant moderating role of organizational factors and organizational performance.

v. There is no significant mediating role of environmental circumstances and organizational performance.

\section{Conclusions and Recommendations}

The objective of this paper is to determine cultural diversity in the workplace and its influence on organizational performance. It is clear that demographic profiles that include age, gender and ethnicity do affect performance of employees in an organization. The differences that are evident in organization culture, human resource practices, nature of work and business strategies mostly impact the 
variable of employee performance, which varies from one company to another. So as to improve knowledge, interaction of organizational culture and national environment, it is necessary to compare the effects of workforce diversity of the same organizations that are situated in different countries. Cultural diversity is further categorized as a primary dimension based on the different definitions of culture that are found. In connection to this, how cultural diversity could affect organizations is presented in terms of how it can be beneficial in certain situations and problematic in others, both in terms of difficulties but also through conflicts. From the literature review, this paper recommends that organizations should have proper cultural diversity management since it enables organizations to achieve a competitive advantage, which in turn influences their performance. In addition organizations should effectively manage their cultural diversity. This is because it has been established that cultural diversity influences organizational performance.

\section{References}

[1] Barney, J. B. (2011). The Future of Resource-Based Theory: Revitalization or Decline? Journal of Management 2011 37: 1299 originally published online 10 March 2011DOI: $10.1177 / 0149206310391805$.

[2] Brauer, M.,\&Wiersema, M. (2012). "Industry Divestiture Waves: How a Firm's Position Influences Investor Returns." Academy of Management Journal. Vol. 55:1472-1492. Business History, 56(3), 372-390.

[3] Carlson, O. (2014). Internationalization of the MBA curriculum and its impact on building students' global competencies.

[4] Dhakshayene, H., \&Anneli, J. (2013). Cultural diversity in organizations: A study on the view and management on cultural diversity

[5] Dike, P. (2013). The impact of workplace diversity on organizations.

[6] Pugliese, A., \&Bezemer, P. J., \&Zattoni, A., \&Huse, M., \&van den Bosch, F. A. J. \&Volberda, H. W. (2009). 'Boards of Directors' Contribution to Strategy.

[7] Ghapanchi, A. H. (2014). Organizational Diagnosis in ProjectBased Companies Challenges and Directions Volume: 4 issue: 2, Article first published online: May 30, 2014; Issue published: June 11, 2014 https://doi.org/10.1177/2158244014537498.

[8] Hackman, J. R., \& Oldham, G. R. (2010). Motivation through the design of work: Test of a theory. Organizational Behavior and Human Performance, 16, 250-279.

[9] Ikama, A. (2010). Benefits and challenges of workplace diversity management: a case study of consultative group on international agricultural research (CGIAR) centres in Kenya organizations journal home page: www.elsevier.com/locate/ijintrel.

[10] Karen, G. (2013). Managing a culturally diverse workforce: Diversity perspectives
[11] Kauppila, O. P. (2015). When and How Does LMX Differentiation Influence Followers' Work Outcomes? The Interactive Roles of One's own LMX Status and Organizational Context Volume 69, Issue 2 Summer 2016 Pages 357-393.

[12] Kogut, B., \& Zander, U. (2012). 'Knowledge of the Firm and the Evolutionary Theory of the Multinational Corporation' Journal of International Business Studies, 4th quarter: 62545. Summary Notes5/25/09 H. Johnson/Michigan State University.

[13] Lockett, A., \& Wild, A. (2014). Bringing history (back) into the resource-based view.

[14] Lundvall, B. A. (2010). National systems of innovation: Toward a theory of innovation and interactive learning (Vol. 2). Anthem Press.

[15] Mayer, R. (2009). Multi-Media Learning, 2nd Ed. Cambridge University Press, NY.

[16] McMahon, A. M. (2010). Does workplace diversity matter? A survey of empirical studies on diversity and firm performance, 2000-09. Journal of Diversity Management, 5(2), 37.

[17] Moore, C. W., \& Woodrow, P. J. (2010). Handbook of global and multicultural negotiation. John Wiley \& Sons.

[18] Murray, B. (2010). Brief profile on disability: Employment for social justice and a fair globalization.http://www.ilo.org/employment/Whatwedo/Publi cations/lang--en/docName--WCMS_140958/index.htm.

[19] Nonaka, T., \&Tayama, R. (2015). Theory of organizational knowledge creation: understanding the dynamic process of creating knowledge.

[20] Nowak, D. J. (2012). Spontaneous giving and calculated greed. Nature, 489, 427-430.

[21] Nowok, B. (2013). 'Does Migration Make You Happy? A Longitudinal Study of Internal Migration and Subjective WellBeing' Environment and Planning A, vol. 45, no. 4, pp. 9861002. DOI: $10.1068 / \mathrm{a} 45287$.

[22] Richard, P. J. (2015). Evolution theory of economic changehb71.n44 338.9'001 81-13455 aacr2 isbn 0-674-272285 (paper).

[23] Teece, D. J. (2010). Explicating dynamic capabilities: The nature and microfoundations of (sustainable) enterprise performance, Strategic Management Journal theorizing about executive compensation. Journal of management (In Press) ISSN 1557-1211DOI: 10.1177/0149206312461054.

[24] Tsoukas, H. (2016). An Introduction to the Special Issue on Managing Complexity Within and Across Organizational Boundaries (pages 129-131).

[25] Tywoniak, J. (2017). Exploring the dynamics of project management office and portfolio management co-evolution: A routine lens. International Journal of Project Management. (In Press).

[26] Wambari, M. N. (2014). Workplace diversity management effects on implementation of human resource management practices in the Ministry of Health, Kenya.

[27] Wiersema, M. F., \& Bowen, H. P. (2008). Corporate diversification: The impact of foreign competition, industry globalization, and product diversification. Strategic Management Journal, 29(2), 115-132. 
[28] Yen, K. (2012). Innovation, customer attachment source in retail service empirical research in day retail.

[29] Penrose, E. T. (1959). The Theory of the Growth of the Firm. New York: John Wiley.

[30] Pepper, A., Gore J. (2015). Behavioural Agency Theory: New Foundations for Theorizing About Executive Compensation. Journal of Management 2012. Originally published online 27 September 2012 DOI/ABS/10.1177/0149206312461054.

[31] Oldham, G., Fried Y. (2016). Job Design Research and Theory: Past, Present and Future. Journal of Organizational behavior and Human Decision processes. 2016. Originally published online 14 September 2016 DOI/ABS/10.1177/0149206312461054.
[32] Grant, R. (2015). The Resource-Based Theory of Competitive Advantage: Implications for Strategy Formulation. California Management Review.

[33] Priem, R., Butler, J., \& Li, S. (2013). Toward reimagining strategy research: Retrospection and prospection on the 2011 AMR decade award article. Academy of Management Review.

[34] Pieters, C. (2014, August 12). The effective management of a culturally diverse workforce in five-star multinational hotels: a case study, the Westin Dublin. Retrieved from http://hdl.handle.net/10788/2087. 